\title{
TEM Study of Mechanically Alloyed and Hot Extruded Aluminum Composite Reinforced with Graphite.
}

\author{
"J.L. Hernández, ${ }^{*}$ R.M. Sánchez, ${ }^{* *}$ J.J. Cruz, ${ }^{*}$ C. Ornelas, ${ }^{* *}$ C. Elías \\ *Centro de Investigación en Materiales Avanzados, Miguel de Cervantes 120, C.P. 31109 , \\ Chihuahua, México. \\ **Facultad de Ingeniería-Instituto de Metalurgia, Universidad Autónoma de San Luis Potosí, Sierra \\ Leona 550, Lomas $2^{\mathrm{a}}$ sección, C.P. 78210, SLP, México.
}

Mechanical alloying and hot processing techniques are some of the most promising processes to fabricate aluminum composites due to the homogenous microstructure obtained. Also, combining these techniques is possible to form a nanostructured material; it means a material on which the grain or crystallite size has been reduced under $100 \mathrm{~nm}[1,2]$.

In this work it have been tried to take the advantages of using solid state processes to obtain 2024 aluminum alloy composite starting from elemental powders and graphite as a reinforcement in order to avoid the drawbacks, such as intermetallics formation, that typically appeared when liquid processes are used to produce these kind of materials [3].

The composite was obtained through mechanical alloying for several times and graphite contents, sintering at $500{ }^{\circ} \mathrm{C}$ for $3 \mathrm{hr}$ and finally hot extrusion process at $500{ }^{\circ} \mathrm{C}$.

STEM (Scanning Transsmition Electron Microscope) micrographs of the extruded condition are shown in figure 1A and 1B. It could be seen that substructure was developed inside the grains of the matrix. It has been reported in the literature that formation of this substructure is typical on aluminum alloys when hot processed [4]. The important issue is that this substructure was obtained in a nanometer level. It is supposed that this fact was enhanced by the fine microstructure scale that resulted after the composite powders were mechanically milled. In a previous work, the same research group documented a nearly $50 \mathrm{~nm}$ crystallite size after mechanically alloying for $5 \mathrm{~h} \mathrm{[5].}$

HRTEM (High Resolution Transsmition Electron Microscope) observations helped to find that the interface between the graphite and Al matrix was found to be of an amorphous character [Fig. 2A and $2 \mathrm{~B}$ ]. It is expected that mechanical properties to be displayed by this composite would be better than the ones fabricated by different ways owing to the absence of a brittle interfacial reaction products such as $\mathrm{Al}_{4} \mathrm{C}_{3}$.

On the other hand, $\mathrm{Al}_{4} \mathrm{C}_{3}$ nanoparticles were evidenced to be dispersed through the microstructure, however it is hard to assume that this phase was formed from a reaction between aluminum and graphite used as a reinforced but also from residual elements contained in the aluminum microstructure (Fig. 3A y 3B). Nowadays, a further study is being carried out in order to find how microstructural features described in the last paragraphs modify mechanical properties.

\section{References}

[1] C. Suryanarayana, Prog. Mat. Sci., 46, 2001, 122-125.

[2] Li Lu et al., Progress, Kuwler Academic Press, 1998, London, 133-135.

[3] K. Chawla et al., Composite Materials: Science Enginnering, Springer Science, USA, 1998, 6684.

[4] P. Trivedi et al., Int. Journal Plasticity, 20, 2004, 459-476.

[5] J.L. Hernandez et al., XVIII Int. Mat. Res. Cong., Cancun, Mex., (2009). 

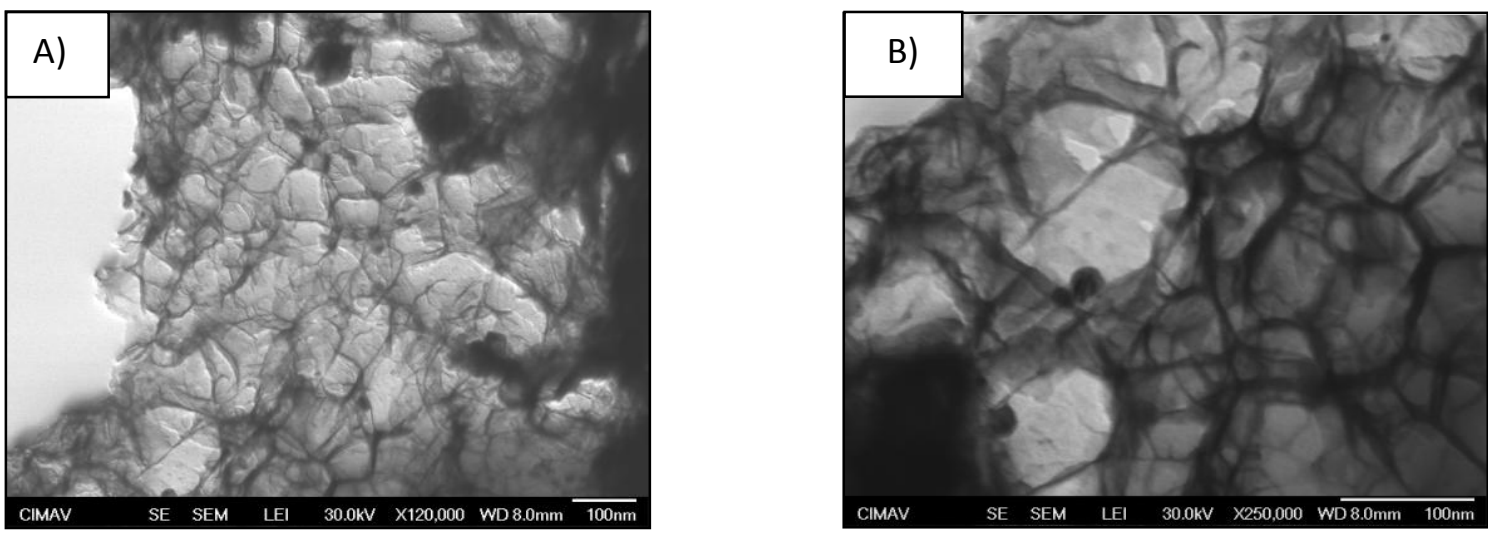

FIG.1. A) and B), STEM micrographs showing substructure developed in the aluminum grains during hot extrusion.
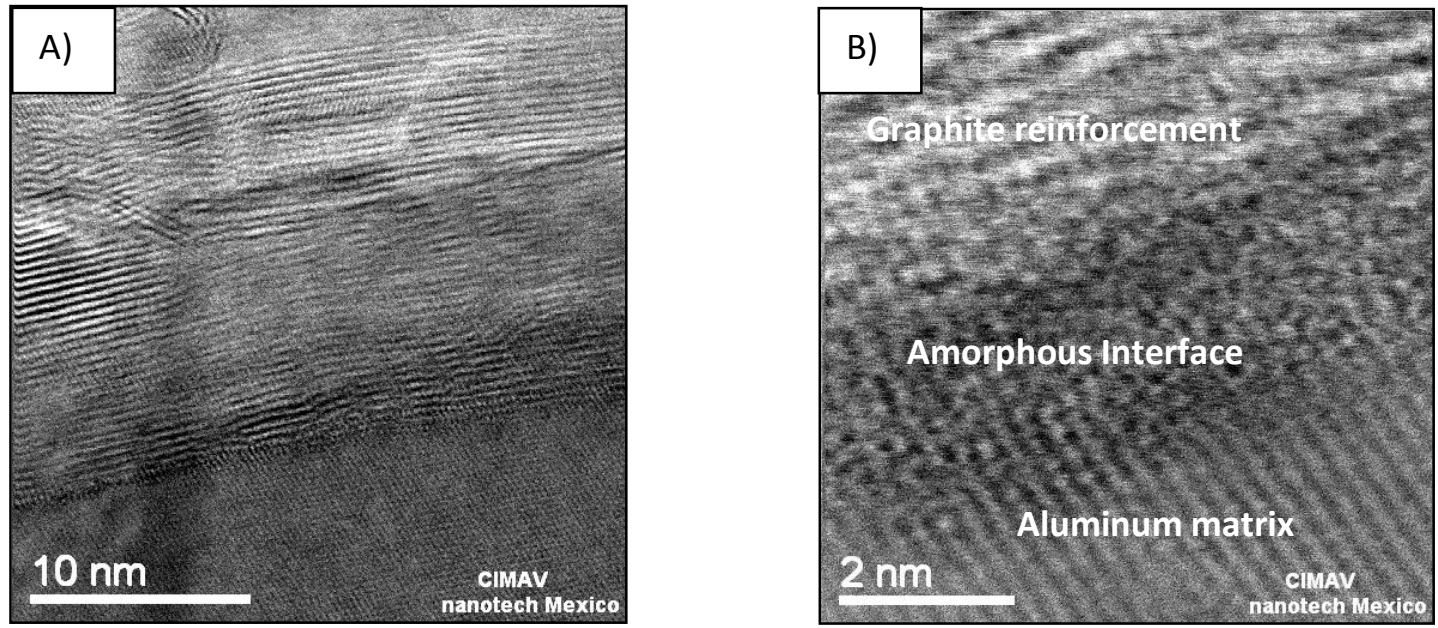

FIG.2. A) HRTEM micrograph of interfacial zone between matrix and reinforcement, B) Closer view of interfacial microstructure.
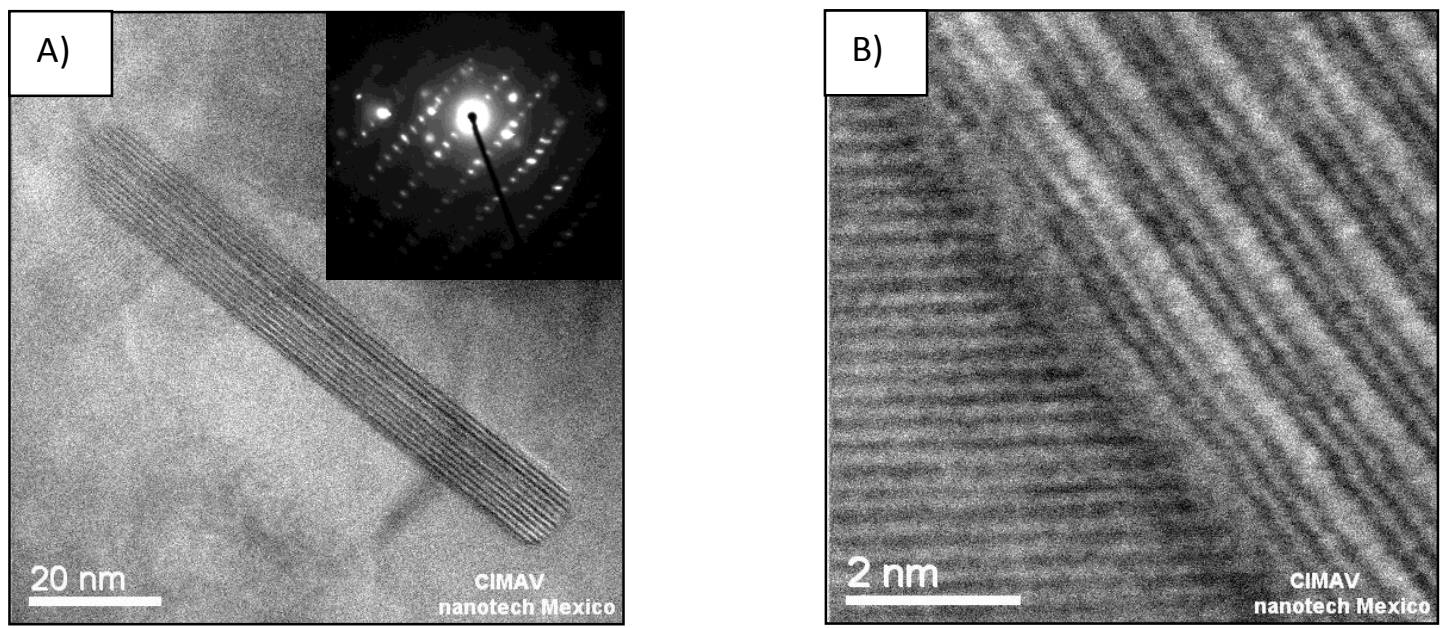

FIG.3. A) HRTEM micrograph with corresponding SADP of hexagonal $\mathrm{Al}_{4} \mathrm{C}_{3}$ plates $\mathrm{B}$ ) Interface formed between aluminum matrix and intermetallic $\mathrm{Al}_{4} \mathrm{C}_{3}$. 